\title{
ANALYSIS OF NATIVE AND ALKALI-TREATED AGAR FROM SPECIES OF Gracilaria (GRACILARIACEAE， RHODOPHYTA) COLLECTED FROM MORIB, MALAYSIA.
}

\author{
Kar-Mun Chung ${ }^{1}$, Sze-Sze Soo ${ }^{1}$, Swee-Sen Teo ${ }^{1 *}$ Siew-Moi Phang ${ }^{2}$ \\ ${ }^{1}$ UCSI University, 1, Jalan Menara Gading, UCSI Heights 56000 Cheras, Kuala Lumpur, Selangor \\ ${ }^{2}$ Institute of Biological Sciences and Institute of Ocean and Earth Sciences, University of Malaya, 50603 \\ Kuala Lumpur, Malaysia. \\ *teoss@ ucsi.edu.my (Corresponding author) \\ Received on $20^{\text {th }}$ July 2011, accepted in revised form $22^{\text {nd }}$ July 2011.
}

\begin{abstract}
Seaweeds are marine algae commonly found in brackish water to marine environments. The red seaweed Gracilaria (Gracilariaceae, Rhodophyta) is commonly exploited for the production of agar. Alkaline pre-treatment has been shown to increase the quality of agar in previous studies. The aim of this study was to compare the effect of native ( untreated) and alkali treatment on the yield and physical properties of agar from Gracilaria changii (Xia \& Abbott) Abbott, Zhang \& Xia, Gracilaria salicornia (C.Agardh) Dawson and Gracilaria edulis (Gmelin) Silva collected from Morib in Malaysia. Compared to native samples (control), an addition of alkali pre-treatment step which involved soaking samples with $0.5 \mathrm{M} \mathrm{NaOH}$ for 1 hour at room temperature prior to extraction was included for the treated samples. Comparative analysis showed that alkali-treated agar of G. edulis gave the highest agar yield $(82.56 \%)$ whereas the highest gel strength was obtained from native agar of G. salicornia $(430 \pm$ $17.32 \mathrm{~g} \mathrm{~cm}^{-2}$ ). Alkali treatment was found to be effective only for the increase of gel strength in $G$. edulis but not in G. changii and G. salicornia. The native and alkali-treated agars in all species gave comparable gelling and melting temperature which were in the range of $\left(36-39^{\circ} \mathrm{C}\right)$ and $\left(80-87^{\circ} \mathrm{C}\right)$ respectively. The overall results showed that $G$. salicornia had superior agar quality and is thus a potentially good source for industrial use. Analysis on chemical properties of agars can be performed in future to determine the agar composition of these species.
\end{abstract}

(Key words: agar; gel strength; Gracilaria; red seaweed; physical properties; yield)

\section{INTRODUCTION}

Agar is a colloid, or a gelatinous substance derived from seaweeds belonging to the Rhodophyceae which includes the orders Gelidiales and Gracilariales (Pereira-Pacheco et al. 2007). Agar is also known as a type of polysaccharide or a matrix component extracted from cell walls of red seaweeds ( $\mathrm{Li}$ et al. 2008) which functions as the primary structural support for the algae cell walls. Agar consists of a mixture of neutral agarose and charged agaropectin (Santos 1990). The basic repeat of the polysaccharide is agarobiose (galactose) which consists of alternating 4-O-3,6-anhydro- $\alpha$ L-galactopyranose and 3-O- $\beta$-D-galactopyranose (Lahaye and Yaphe 1988). The yield and physical properties of agar as well as the chemical characteristics determine its value in the industry (Marinho-Soriano 2001). Agar is important for industrial use due to its excellent thickening and gelling properties. The parameters which determine its quality includes the gel strength, gelling and melting temperatures, viscosity, sulphate content, 3,6anhydrogalactose content and syneresis index (lost of water during ageing) (Pereira-Pacheco et al. 2007).

Gracilaria is the major world-wide agar source (Freile-Pelegrin and Murano 2005) and can be found in temperate as well as in tropical countries (Santos 1990). Gracilaria species have become an important source of agar due to the shortage of Gelidium species (Pereira-Pacheco et al. 2007). Gracilaria changii is the most 
abundant agarophytic seaweed found in Malaysia and is recently cultured mainly for production of agar (Phang et al. 1996). This species can be found in west and east coast of peninsular Malaysia (Phang 2006). G. changii is a good source of high quality agar and agarose and has been experimentally cultivated in shrimp ponds, mangrove ponds and water supplying canals (Phang et al. 1996). Generally, native agars of Gracilaria species are low in quality due to high sulfate content which produces low gel strength of agar. Hence, alkali pre-treatment is used prior to the agar extraction step in order to eliminate the sulphate groups and enhance their gel forming ability (Pereira-Pacheco et al. 2007). However, the low gel strength of the native agars of this genus, together with their low syneresis, allow their use as gelling agents for spread foods, soft-texture confectionery and as emulsifier (Freile-Pelegrin and Murano 2005).

The gel strength and agar constituent vary with species, location, season and extraction method (Marinho-Soriano 2001). According to MarinhoSoriano (2001), gel strength of agar is speciesspecific although the samples were collected from the same location or share the same environmental conditions. In traditional extraction protocol of agar, a chemical is used as the bleaching agent ( $\mathrm{Li}$ et al. 2008). Pretreatment with alkali and acid on the raw material using $1 \mathrm{~N} \mathrm{NaOH}$ and $0.5 \%$ acetic acid before agar extraction has been applied (Roleda et al. 1997). Previous studies from FreilePelegrin and Murano (2005) reported that alkaline treatment strongly improved the gel strength and increased both gelling and melting temperatures of agar extracted from Gracilaria crassissima. The gel strength of this species was improved to $1390 \mathrm{~g} \mathrm{~cm}^{-2}$ in $7 \% \mathrm{NaOH}$ treated agar. The gelling temperature was also increased to $50^{\circ} \mathrm{C}$ while the melting temperature was increased to $93^{\circ} \mathrm{C}$ after the native agar was treated with $7 \% \mathrm{NaOH}$. However, the study from Freile-Pelegrin and Murano (2005) showed that the gel strength, gelling temperature and melting temperature of agar extracted from Gracilaria cervicornis and Gracilaria blodgettii were not affected by alkaline treatment. A study from Buriyo and Kivaisi (2003) also showed that alkali treatment reduced the yield of agar (\% dry weight) by almost $25-56 \%$ for Gracilaria salicornia in Tanzania.

This study was aimed to determine the quality of agars from $G$. changii, $G$. salicornia and $G$. edulis collected from the mangroves at Morib, Malaysia and to study the effect of alkali pretreatment during agar extraction, on the yield, gelling and melting temperatures as well as the gel strength of the extracted agars.

\section{MATERIALS AND METHODS}

G. changii, G. salicornia and $G$. edulis were collected in August 2009 at Morib (02 ${ }^{\circ}$ 45.808' $\left.\mathrm{N} ; 101^{\circ} 26.143^{\prime} \mathrm{E}\right)$, west coast peninsular Malaysia. The samples were washed thoroughly with tap water to remove the epiphytes and impurities. The samples were sun-dried and kept in a plastic bag to store at $-80^{\circ} \mathrm{C}$ freezer until agar extraction in the laboratory. Samples of the three Gracilaria species were prepared as herbarium specimens for record.

\section{Agar extraction.}

The native agar extraction was performed according to the method described by Phang et al. (1996) with some modifications. Dried samples of $G$. changii, $G$. salicornia and $G$. edulis (10g), respectively were immersed separately in $300 \mathrm{ml}$ of distilled water for 10 minutes and heated for $15 \mathrm{~min}$ at $121^{\circ} \mathrm{C}$ in an autoclave. The hot solution was filtered through filter cloth $(10 \mathrm{~cm} \times 4 \mathrm{~m}$ cotton crepe bandage) (AnjiWande Medical Products Co. Ltd., China) to remove the algal residue. The filtrates were transferred into a beaker to gel at room temperature $\left(24^{\circ} \mathrm{C}\right)$ and frozen overnight at $20^{\circ} \mathrm{C}$. The frozen gel was thawed on the next day at room temperature. The thawed water was drained to remove the soluble impurities. The agar was then washed with $100 \mathrm{~mL} \mathrm{95 \%}$ isopropanol, followed by $100 \mathrm{~mL} 80 \%$ isopropanol. All the isopropanol was discarded and all the gel in the beaker was transferred into an empty petri dish $(145 / 20 \mathrm{~mm}$, Greiner bioone, Germany) to dry at $50^{\circ} \mathrm{C}$ until the weight was constant for agar yield determination. Alkali-treated agar extraction was carried out where the sample was being immersed in 300 $\mathrm{mL}$ of distilled water for 10 minutes followed by a few drops of $0.5 \mathrm{M} \mathrm{NaOH}$ being added into the soaked samples and incubated at room temperature for 1 hour. The $\mathrm{pH}$ of the agar suspension was then adjusted to $\mathrm{pH} 8$. After that, the extraction and other remaining processes were carried out as in the native agar extraction. All the agar extractions were done in triplicate for each species. The agar yield of each replicate 
was calculated as the percentage of dry matter based on the following formula:

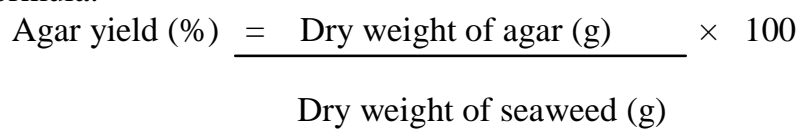

\section{Physical properties determination.}

Gelling and melting temperatures and gel strength of agar were determined on $1.5 \%(\mathrm{w} / \mathrm{v})$ agar solutions. Gel strength determination was carried out using a Nikkansui Gel Strength tester on $1.5 \%$ gel. The gelling temperature was determined from the melted agar solution in the test tube $(15 \times 120 \mathrm{~mm})$ which was allowed to gel slowly at room temperature $\left(24^{\circ} \mathrm{C}\right)$. The test tube was then constantly moved (inclined to a $45^{\circ}$ angle). A thermometer was inserted into the agar and the temperature was recorded as the gelling temperature when the solution was stopped

Herbarium specimens were prepared with different thalli of G. changii G. salicornia and $G$. edulis on herbarium mounting paper for the comparison of morphological characteristics (Figure 1). The colour observed for G. changii was purplish while it was yellowish to reddish colour observed for G. edulis. The colour for $G$. salicornia was slightly darker than that of $G$. changii. G. changii had thicker and longer thalli compared to G. edulis. Both species had irregular branching and G. edulis was found to be attached closely to form thick bunches. G. edulis has fastigiated branches with bifurcate tips. There are segments separated by constrictions along the thallus of G. salicornia compared to G. changii which had constriction at point of insertion of branches.

\section{RESULTS}

a)

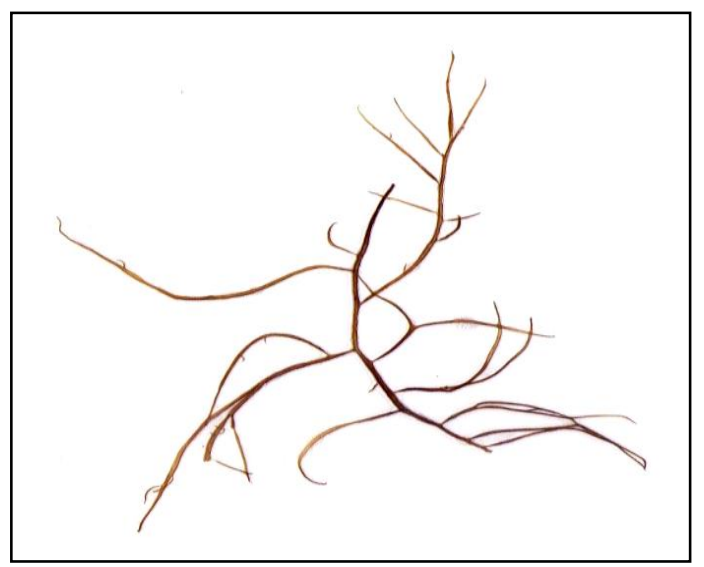

moving or the agar did not flowed back to form a normal meniscus.

The melting temperature was determined from the gelled agar in the test tube $(15 \times 120 \mathrm{~mm})$ which was placed in a $60^{\circ} \mathrm{C}$ water bath. At the same time, a small metal bead (diameter $2 \mathrm{~mm}$ ) was placed on the surface of each gelled agar sample. The temperature of the water bath was gradually raised at $1{ }^{\circ} \mathrm{C}$ per minute and the temperature when the bead fell until the bottom of the test tube was recorded as the melting temperature.

The thallus of G. salicornia was also thicker than both G. changii and G. edulis. While it is diffult to separate the life - stages of Gracilaria plants in the field when they are immature, female plants are easily identified through presence of the cystocarp. Cystocarps are formed after sexual reproduction, and produce diploid carpospores which when released, germinate back into the diploid sporophyte. The samples used for this study could not be verified for the life-stage as no reproductive structures were observed. Male and female gametophytic plants were reported to be found in similar proportions throughout the year but tetrasporic plants were usually in greater numbers (Phang et al. 1996)

b)

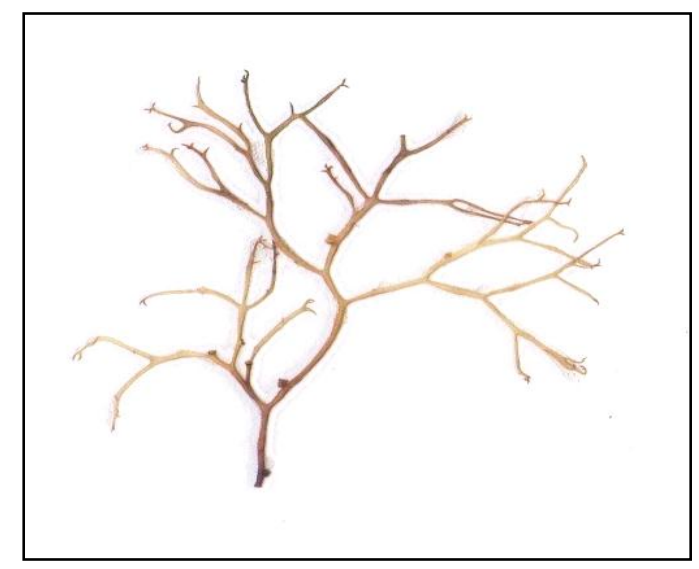


c)

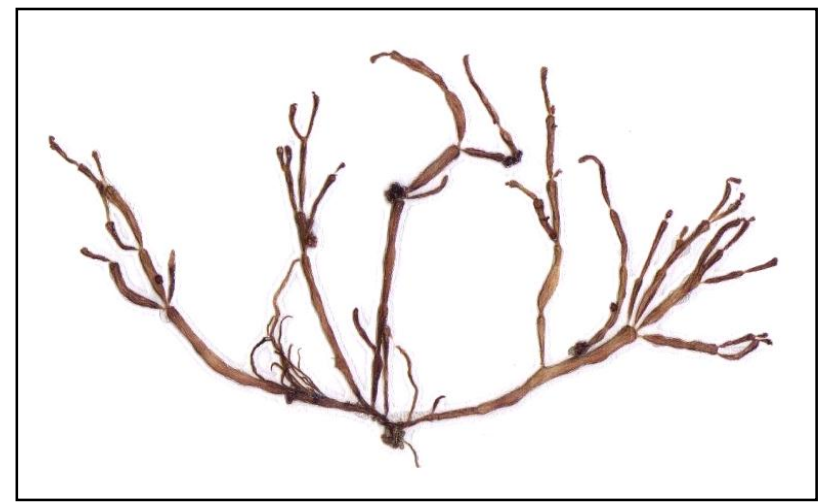

Figure 1. Herbarium of Gracilaria species. a) G. changii. b) G. edulis. c) G. salicornia

Table 1. Yield and physical properties of 1.5\% (w/v) agar extracted from G. changii, G. salicornia and G. edulis using different extraction methods. (Average $\pm \mathrm{SD}, \mathrm{n}=3$ )

\begin{tabular}{|c|c|c|c|c|c|c|}
\hline & \multicolumn{2}{|c|}{ G. changii } & \multicolumn{2}{|c|}{ G. salicornia } & \multicolumn{2}{|c|}{ G. edulis } \\
\hline & Native & $\begin{array}{l}\text { Alkali- } \\
\text { treated }\end{array}$ & Native & $\begin{array}{l}\text { Alkali- } \\
\text { treated }\end{array}$ & Native & $\begin{array}{l}\text { Alkali- } \\
\text { treated }\end{array}$ \\
\hline $\begin{array}{l}\text { AgarYield (\% } \\
\text { Dry Wt) }\end{array}$ & $\begin{array}{c}39.33 \pm \\
16.40\end{array}$ & $40.79 \pm 4.49$ & $63.89 \pm 2.41$ & $79.17 \pm 5.01$ & $69.75 \pm 5.82$ & $82.56 \pm 5.40$ \\
\hline $\begin{array}{l}\text { Gelling } \\
\text { Temperature } \\
\left({ }^{\circ} \mathrm{C}\right)\end{array}$ & $38.7 \pm 1.2$ & $36.3 \pm 3.0$ & $37.7 \pm 1.5$ & $39.0 \pm 1.0$ & $38.3 \pm 0.6$ & $37.7 \pm 0.6$ \\
\hline $\begin{array}{l}\text { Melting } \\
\text { Temperature } \\
\left({ }^{\circ} \mathrm{C}\right)\end{array}$ & $80.0 \pm 1.7$ & $80.3 \pm 2.3$ & $81.0 \pm 3.6$ & $84.3 \pm 3.1$ & $86.3 \pm 0.6$ & $81.0 \pm 3.0$ \\
\hline $\begin{array}{l}\text { Gel Strength } \\
\left(\mathrm{g} \mathrm{cm}^{-2}\right)\end{array}$ & $400 \pm 17$ & $370 \pm 62$ & $430 \pm 17$ & $385 \pm 61$ & $295 \pm 85$ & $365 \pm 31$ \\
\hline
\end{tabular}


In the present study, alkaline treatment markedly improved the agar yield from G. salicornia and $G$. edulis but had little effect on agar fractions from G. changii. All the alkali-treated agar of these three species had higher yield as compared to the native samples (Table 1). However, the agar yield obtained from all the three Gracilaria species in this study were higher than those found in the literature. The minimum agar yield shown in samples of $G$. changii $(39.33 \pm 16.40$ $\%)$, G. salicornia $(63.89 \pm 2.41 \%)$ and also in $G$. edulis $(69.75 \pm 5.82 \%)$ were considered very high compared with the results obtained from Buriyo and Kivaisi (2003) on native samples of G. salicornia (25\%), G. changii (12-25\%) and G. edulis (17.9\%) from Malaysia (Phang et al. 1996).

The highest gelling temperature $\left(39.0 \pm 1.0^{\circ} \mathrm{C}\right)$ was measured on agar gels from alkali-treated $G$. salicornia while the lowest gelling temperature $\left(36.3 \pm 3.0^{\circ} \mathrm{C}\right)$ was measured on agar gels from alkali-treated sample of $G$. changii. The higher gelling temperature is suitable for laboratory applications since the liquid agar does not require low temperature and can save time for it to solidify. There was no marked difference for gelling temperature between the three species with the range of $\left(36-39^{\circ} \mathrm{C}\right)$. This range of gelling temperature is acceptable for agar according to the United States Pharmacopoeia (USP) ( $\mathrm{Li}$ et al. 2008). However, there was a slight decrease in the gelling temperature after alkaline treatment on G. changii and G. edulis, similar to the finding from Praiboon et al. (2006) who reported that gelling temperatures were generally lower for alkali-treated agar especially on G. edulis. The results for all of the species in this study were considered lower than expected where agars extracted from Gracilaria species will usually gel at $30-50^{\circ} \mathrm{C}$ (Santos 1990).

The melting temperatures for agar from both of the species were in the range of $\left(80-86^{\circ} \mathrm{C}\right)$. Native sample of G. edulis gave an unexpected high melting temperature $\left(86.3 \pm 0.6^{\circ} \mathrm{C}\right)$ among all the samples in this study. The lowest melting temperature $\left(80.0 \pm 1.7^{\circ} \mathrm{C}\right)$ was measured on agar from native sample of $G$. changii and the melting temperature of this species was not affected by alkaline treatment which gave almost the similar value $\left(80.3 \pm 2.3^{\circ} \mathrm{C}\right)$. Alkaline treatment increased the melting temperature of agar from $G$. salicornia but there was a decrease in melting temperature observed in $G$. edulis after alkaline treatment.
The gel strength of agars extracted from $G$. changii ranged between $300-420 \mathrm{gcm}^{-2}, G$. salicornia range from $330-450 \mathrm{gcm}^{-2}$ while the range in agars extracted from $G$. edulis was between 225-390 gcm was obtained from native sample of $G$. salicornia while the lowest value was obtained from native sample of $G$. edulis. Alkaline treatment was effective in increasing the gel strength in G. edulis but not in G. changii and $G$. salicornia.

\section{DISCUSSION}

The Gracilaria used in this study were collected during the rainy season and this may be the reason that the plants were smaller, and may have lower agar yield and gel strength. According to Phang et al. (1996), thalli of Gracilaria changii in Thailand were found throughout the year at one locality but seasonal variation occurred at two other locations where thalli were only found in two periods (January to July and March to September). This compared well with the condition in Philippines by Marinho-Soriano (2001) where G. changii was only present for six month especially during the dry season in a year compared to other Gracilaria species. According to them, except for rainfall, all other environmental parameters (temperature, salinity, $\mathrm{pH}$, turbidity) showed insignificant relationship with the biomass of Gracilaria species (Pondevida and HurtadoPonce 1996; Marinho-Soriano 2001). This showed that seasonal variation has significant effect on the biomass and growth of $G$. changii in Malaysia, which may then affect agar yield and gel strength.

In the present study, alkaline treatment had markedly improved the agar yields from all three Gracilaria species. This is contrary to, previous researchers who reported that alkali treatment generally reduced agar yield by $25-56 \%$ (Buriyo and Kivaisi, 2003). The decrease in agar yield after alkali treatment was related to yield loss due to degradation of polysaccharides caused by alkaline hydrolysis during treatment and also agar loss by diffusion during the processing (Armisen and Galatas 1987; Freile-Pelegrin and Murano 2005; McHugh 2003). Hence, the increase of the agar yield in all three Gracilaria species in this study was most probably due to the effectiveness of the alkaline treatment process on more efficient but gentle extraction of 
the agar from the cell walls, which caused no degradation of the polysaccharides. This result was similar as that obtained by Roleda et al. (1997) who reported that alkali pre-treatment Gelidiella acerosa gave high agar yields compared to untreated samples because alkali treatment was observed to soften the tough thalli. Besides that, agar yield from seaweed samples extracted by autoclaving at $121^{\circ} \mathrm{C}$ was slightly higher than that from the seaweed samples extracted in a water bath at $95^{\circ} \mathrm{C}$ (Buriyo and Kivaisi 2003). This showed that the extraction method was important in producing high yield of agar. Variation in agar yield was not only affected by pre-extraction treatment but also related to the extraction time, boiling and applying steam pressure during extraction of the agar (Roleda et al. 1997).

The improved agar yield could be due to other various factors such as the conditions of the environment (Bird 1988; Buriyo and Kivaisi 2003), physiological factors (Lahaye and Yaphe 1988), extraction methods (Freile-Pelegrin and Robledo 1997; Marinho-Soriano 2001) which affect the proportion of the seaweed constituents. Environmental factors which caused higher yield included higher insolation, salinity, temperature and low nitrogen supply (Buriyo 1999; Buriyo and Kivaisi 2003). Another reason for higher agar yield may be the presence of solvents such as ethanol in the seaweed species. Lahaye and Yaphe (1988) showed that sequential solvent extraction with ethanol could prevent the loss of polysaccharides associated with freeze-thaw and alcohol precipitation procedure during the extraction of the agar.

The gelling temperature of agars for all the three species in this study were considered lower than the expected results, where agars extracted from Gracilaria species will usually gel at $40-42^{\circ} \mathrm{C}$ (Armise'n 1993; Phillips and Williams 2000). The low gelling temperatures were probably due to the low methoxyl content of agar (Guiseley 1970; Youngs et al. 1998) although this chemical composition was not established in this study. Besides that, the molecular weight and molecular weight distribution are also parameters which could affect the agar gelling behaviour (FreilePelegrin and Murano 2005). Furthermore, low gelling temperatures might also be due to the long storage of the samples. Enzymatic processes of endogenous and microbial origin might be the cause of agar hydrolysis due to prolonged storage of the samples (Freile-Pelegrin 2000).
There was a decrease in melting temperature to $81.0 \pm 3.0^{\circ} \mathrm{C}$ observed in G. edulis after alkaline treatment. Hisashi et al. (1999) reported that the decrease in melting points of agar were correlated to the shifting of the molecular weight distribution to the lower molecular weight side and with a decrease of the agar molecular weight. The decrease in the melting temperature after alkali treatment may be due to alkali hydrolysis which reduced its molecular weight (Praiboon et al. 2006). The results also showed that native agar of $G$. edulis had the highest melting temperature compared to all the samples. Nevertheless, the agar gel strength of both $G$. changii and $G$. salicornia were higher than $G$. edulis. Hence, the results obtained in this study were in contrast with the study from Lewis and Hanisak (1996) who mentioned that melting temperatures were higher in agars with higher gel strengths.

Different gel strengths were also observed for the native and alkali-treated agar from the samples of the same species. The results were in agreement with the study from Marinho-Soriano (2001) who indicated that gel strength is specific species where the three species of the red seaweeds namely G. gracilis, G. dura and $G$. bursapastoris used in his study were collected from the same location that shared the same environmental conditions but had different gel strengths.

Alkali treatment using sodium hydroxide can improve the quality of agar by converting Lgalactose-6-sulfate to 3,6-anhydro-L-galactose (Armisen, 1995; Marinho-Soriano and Bourret 2005). Thus, alkali-treated agar will have lower sulfate content than the native agar (Praiboon et al. 2006). However, gel strength of agars from $G$. changii and $G$. salicornia in this study was not improved by alkali treatment and was even lower than that found for gel strength of native agar (Table 1). One of the possibilities was that the alkali treatment had slightly reduced the 3,6 anhydrogalactose content but had only little effect on the sulfate content. Moreover, the presence of high sulfate content in tropical agarophytes have been reported to have reduced the agar quality (Buriyo and Kivaisi 2003). The alkali treatment used in the present study should be intensified to result in sulphate reduction in the agar. 
However, alkali treatment in this study had improved the gel strength of the agar from $G$. edulis similar to the report by Praiboon et al. (2006) on agar of G. edulis from Thailand which the native agar had the gel strength of $197.08 \pm$ $72.87 \mathrm{gcm}^{-2}$ and was subsequently increased to $239.95 \pm 28.35 \mathrm{gcm}^{-2}$ in alkali-treated agar. The results in this study was also similar with the results of wild $G$. edulis but was in contrast with the results of cultured $G$. edulis from Malaysia as being reported by Phang et al. (1996) that alkali treatment was not effective for cultured $G$. edulis but had slightly improved the gel strength in wild G. edulis from $276 \pm 7 \mathrm{gcm}^{-2}$ to $331 \pm 20 \mathrm{gcm}^{-2}$. The G. edulis in this study was obtained from the wild and was not the cultured type of seaweed.

The gel strength of agar for both native and alkali-treated agars determined in this study was comparable to values reported in the literature. Praiboon et al. (2006) reported that agar of $G$. edulis from Thailand had gel strength of 197.08 $\pm 72.87 \mathrm{gcm}^{-2}$ and $239.95 \pm 28.35 \mathrm{gcm}^{-2}$ observed in native agar and alkali-treated agar respectively. Buriyo and Kivaisi (2003) reported that the gel strength of $G$. salicornia ranged from 205 to $220 \mathrm{~g} \mathrm{~cm}^{-2}$, which was about $40 \%$ lower than the result obtained for this species in the present study where the gel strength for native and alkali treated $G$. salicornia was $430 \pm$ $17.32 \mathrm{~g} \mathrm{~cm}^{-2}$ and $385 \pm 60.62 \mathrm{~g} \mathrm{~cm}^{-2}$ respectively. Phang et al. (1996) reported that gel strength of native agar from $G$. changii was in the range of $294-563 \mathrm{gcm}^{-2}$. For the seaweeds collected in August 1990, the gel strength for $G$. changii was $368.21 \pm 37.17 \mathrm{~g} \mathrm{~cm}^{-2}$, which was slightly lower than the gel strength of the same species obtained in this present study which was $400 \pm 17.32 \mathrm{~g} \mathrm{~cm}^{-2}$.

Seasonal variation plays an important role although the focus of this research was not in this area. Increased temperatures at the mangrove in Morib during sample collection could cause the increase in sulfate content in agar molecule thus lowering the gel strength (Armisen 1995; Freile-Pelegrin and Murano 2005; MarinhoSoriano and Bourret 2005). However, rainy seasons are related to low salinity which may cause increase of osmotic gradients such that ions like $\mathrm{Ca}^{2+}$ and $\mathrm{K}^{+}$leave the cell into the medium and is also another factor that contributes to the lower gel strength (Lobban and Harrison 1994; Buriyo and Kivaisi 2003). These ions are responsible to increase the gel strength of some species of red seaweeds (Buriyo and
Kivaisi 2003). The seaweed samples used in this study were not dried prior to agar extraction; instead fresh samples were used. According to Santos (1990), the moisture content of the dry sample must be in the range of 15-20\% because very moist samples may be expose to rapid deterioration and thus produce low quality agar.

The gelling and melting temperature specifications for bacteriological agar according to the American Society of Microbiology Specification (Meer 1980; Roleda et al. 1997) are $33-38^{\circ} \mathrm{C}$ and $80 \pm 5^{\circ} \mathrm{C}$ respectively with the temperature hysteresis of $42-52^{\circ} \mathrm{C}$. Therefore, the results in this study showed that the agar extracted from $G$. salicornia having the gelling temperature of $37-39^{\circ} \mathrm{C}$ and melting temperature of $81-84.3^{\circ} \mathrm{C}$ with temperature hysteresis range between $43.3-45.3^{\circ} \mathrm{C}$ for both the native and alkali-treated agar were the best source among the all the samples in this study applicable for bacteriological grade agar. In addition to that, the agar yield obtained from this species was quite high although overall the highest agar yield was observed from G. edulis. Furthermore, the gel strength of native agar from $G$. salicornia was the highest among the three species in which alkaline treatment was not effective to increase the gel strength of agar from this species.

For future studies, variables and parameters such as the concentration of $\mathrm{NaOH}$, temperature and time of extraction on native and alkalitreated agar should be studied in order to determine optimum extraction conditions for the yield, gel strength, gelling temperature and melting temperature of agar. The extraction method still can be improved for the increase in gel strength since alkaline treatment has been observed to have no significant effect on the agar quality in $G$. changii and $G$. salicornia. For example, extraction with hot alkaline treatment (Phang et al. 1996) and prolonged incubation time. Further research is required to collect samples in various seasons and with more replicates to obtain more accurate results. Further chemical analysis on the content of 3,6-anhydroL-galactose, sulphur content, methoxyl and pyruvic acid ketal content in agar and NMR spectroscopic studies are also needed so that the chemical structure of the agar can be explained in detail. 


\section{ACKNOWLEDGEMENT}

This study was supported by the Faculty of Applied Science, UCSI University. Prof. Dr. Phang Siew Moi (Institute of Biological Sciences, Faculty of Science, University Malaya, Malaysia) provided the seaweed samples.

\section{REFERENCES}

1. Armisen R, Galatas, F (1987) Production, properties and uses of agar. In McHugh DJ (Ed.), Production and Utilisation of Products from Commercial Seaweeds. (pp. 1-57). FAO Fisheries Technical Paper

2. Armise'n R (1993) 'Agar-Agar'. Lecture in Training Course T004 'Gels Thickeners and Stabilizing Agents' held in Leatherhead, Surrey, UK on 25-8 May 1993 organised by Leatherhead Food Research Association. In Phillips, G.O. and Williams, P.A. 2000. Handbook of hydrocolloids, Woodhead Publishing Limited and CRC Press LLC

3. Armisen R (1995) World-wide use and importance of Gracilaria. Journal of Applied Phycology 7: 231-243.

4. Bird KT (1988) Agar production and quality from Gracilaria sp. strain G-16: effects of environmental factors. Botanical Marina 31: 33-39.

5. Buriyo AS (1999) The effect of seasons on yield and quality of agar and carrageenan from selected Tanzanian red algal species. MSc thesis, University of Dar es Salaam, Tanzania

6. Buriyo AS, Kivaisi AK (2003) Standing stock, agar yield and properties of Gracilaria salicornia harvested along the Tanzanian Coast. Western Indian Ocean Journal of Marine Science 2(2): 171-178

7. Freile-Pelegrin Y, Robledo D (1997) Influence of alkali treatment on agar from Gracilaria cornea from Yucatan, Me'xico. Journal of Applied Phycology 9: 533-539.
8. Freile-Pelegrin Y, Murano E (2005) Agars from three species of Gracilaria (Rhodophyta) from Yucatan Peninsula. Bioresource Technology 96(3): 295-302

9. Guiseley KB (1970) The relationship between methoxyl content and gelling temperature of agarose. Carbohydrate Research 13(2): 247-256.

10. Hisashi $\mathrm{S}$, Yoshinori $\mathrm{S}$, Mitsuro $\mathrm{T}$ (1999) Molecular weight of agar by high temperature type gel permeation chromatography and physical properties. Journal of the Japanese Society for Food Science and Technology 46: 821-826

11. Lahaye M, Rochas C, Yaphe W (1986) A new procedure for determining the heterogeneity of agar polymers in the cell walls of Gracilaria spp. (Gracilariceae, Rhodophyta). Canadian Journal of Botany 64: 579-585.

12. Lahaye M, Yaphe W (1988) Effect of seasons on the chemical structure and gel strength of Gracilaria pseudoverrucosa agar (Gracilariaceae, Rhodophyta). Carbohydrate Polymers 8: 285-301

13. Lewis RJ, Hanisak MD (1996) Effects of phosphate and nitrate supply on productivity, agar content and physical properties of agar of Gracilaria strain G-16S. Journal of Applied Phycology 8(1): 41-49

14. Li H, Yu X, Jin Y, Zhang W, Liu Y (2008) Development of an eco-friendly agar extraction technique from the red seaweed Gracilaria lemaneiformis. Bioresource Technology 99(8): 33013305

15. Marinho-Soriano E (2001) Agar polysaccharides from Gracilaria species (Rhodophyta, Gracilariaceae). Journal of Biotechnology 89(1): 81-84

16. Marinho-Soriano E, Silva TSF, Moreira WSC (2001) Seasonal variation in the biomass and agar yield from Gracilaria cervicornis and Hydropuntia cornea 
from Brazil. Bioresource Technology 77(2): $115-120$

17. Marinho-Soriano E, Bourret E (2005) Polysaccharides from the red seaweed Gracilaria dura (Gracilariales, Rhodophyta). Bioresource technology 96(3): 379-82

18. McHugh DJ (Ed.), Production and Utilisation of Products from Commercial Seaweeds. (pp. 1-57). FAO Fisheries Technical Paper

19. Meer W (1980) Agar. In Davidson R (Ed.), Handbook of Water Soluble Gums and Resins (pp. 1-17) New York: McGraw-Hill

20. Murano E, Toffanin R, Zanetti F, Knutsen SH, Paoletti S, Rizzo R (1992) Chemical and macromolecular characterisation of agar polymers from Gracilaria dura (C. Agardh) J. Agardh (Gracilariaceae, Rhodophyta). Carbohydrate Polymers 18: 171-178

21. Oyieke HA (1993) The yield, physical and chemical properties of agar gel from Gracilaria species (Gracilariales, Rhodophyta) of the Kenya Coast. Hydrobiologia 260/261: 613-620.

22. Pereira-Pacheco F, Robledo D, Rodriguez-Carvajal L, Freile-Pelegrin Y (2007). Optimization of native agar extraction from Hydropuntia cornea from Yucatan, Mexico. Bioresource Technology 98(6): 1278-1284

23. Phang SM, Shaharuddin S, Noraishah H, Sasekumar A (1996) Studies on Gracilaria changii (Gracilariales, Rhodophyta) from Malaysian mangroves. Hydrobiologia 326/327: 347-352

24. Phang SM (2006) Seaweed resources in Malaysia: Current status and future prospects. Aquatic Ecosystem Health \& Management 9(2): 185-202

25. Pondevida HB, Hurtado-Ponce AQ (1996). Assessment of some agarophytes from the coastal areas of Iloilo, Philippines I. Seasonal variations in the biomass of Gracilaria changii,

Gracilaria manilaensis and Gracilariopsis bailinae (Gracilariales, Rhodophyta). Botanica Marina 39(2): 117-122.

26. Praiboon J, Chirapart A, Akakabe Y, Bhumibhamon O, Kajiwara T (2006). Physical and Chemical Characterization of Agar Polysaccharides Extracted from the Thai and Japanese Species of Gracilaria. ScienceAsia 32(1): 11-17

27. Roleda MY, Montano NE, GanzonFortes ET, Villanueva RD (1997) Acetic acid pretreatment in agar extraction of Philippine Gelidiella acerose (Forsskaal) Feldmann et Hamel (Rhodophyta, Gelidiales). Botanica Marina 40(1): 63-69

28. Santos GA (1990) A Manual for the Processing of Agar from Gracilaria. Asean/UNDP/FAO Regional Smallscale Coastal Fisheries Development Project

29. Youngs HL, Gretz MR, West JA, Sommerfeld MR (1998) The cell wall chemistry of Bangia atropurpurea (Bangiales, Rhodophyta) and Bostrychia moritziana (Ceramiales, Rhodophyta) from marine and frestwater environments. Phycological Research 46: 63-73 